\title{
Porous Cobalt Sulfide Selenium Nanorods for Electrochemical Hydrogen Evolution
}

\author{
Zhengtian Shi, ${ }^{\dagger}$ Xiangqian Qi, ${ }^{\dagger}$ Zhiyuan Zhang, ${ }^{\dagger}$ Yingchao Song, Jianfa Zhang, Chucai Guo, \\ and Zhihong Zhu*
}

Cite This: ACS Omega 2021, 6, 23300-23310

Read Online

ABSTRACT: A key process in electrochemical energy technology is hydrogen evolution reaction (HER). However, its electrochemical properties mainly depend on the catalytic activity of the material itself. Therefore, it is important to find efficient electrocatalysts to realize clean hydrogen production. As a typical kind of catalytic materials, transition metal dichalcogenides (TMCs) play important roles in the field of energy catalysis. As a representative of TMCs, cobalt disulfide $\left(\mathrm{CoS}_{2}\right)$, recently has raised much research interest owing to its abundant reserves, environmental

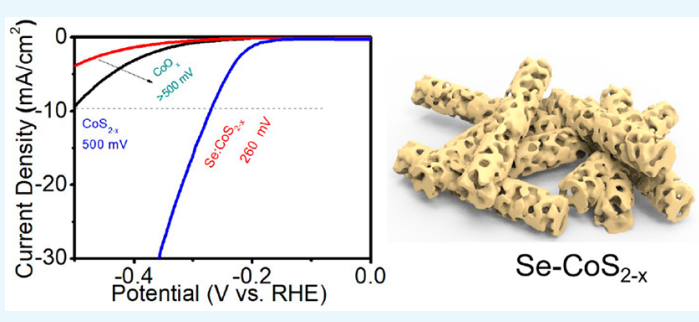
friendliness, and excellent electrochemical stability. Meanwhile, given the fact that doping is one of the effective methods to improve the electrochemical catalytic property, various means of doping have been researched. Here, we report for the first time that porous-like $\mathrm{Se}-\mathrm{CoS}_{2-x}$ (or Se: $\mathrm{CoS}_{2-x}$ ) nanorod can be facilely synthesized via a controllable two-step strategy. It is demonstrated that doping Se can greatly improve the catalytic performance of CoS ${ }_{2}$ electrode. The electrode can obtain a current density of $10 \mathrm{~mA} \mathrm{~cm}$ at overpotential of only $\sim 260 \mathrm{mV}$. And the current changes with the applied bias voltage in an obvious stepped pattern, in the chronopotential (CP) curve of $\mathrm{Se}-\mathrm{CoS}_{2-x}$, indicating its outstanding mass transfer property and mechanical stability.

\section{INTRODUCTION}

When it comes to the current energy problem, conventional energies such as coal, petroleum, natural gas fail to provide a feasible solution for their shortcomings of being nonrenewable, pollutional, and harmful during the combustion process. ${ }^{1-3}$ That is why it is necessary to seek new renewable clean energy sources, among which, hydrogen may act as a perfect candidate. The most direct approach to obtain hydrogen is splitting water. ${ }^{4}$ However, a certain amount of energy (such as additional bias voltage) is required during this process. Therefore, to realize clean hydrogen production, highefficiency catalysts have been researched in recent years, e.g., platinum- (Pt-) based alloys. ${ }^{5-7}$ Nevertheless, although highperformance, the expensive cost and limited reserves of $\mathrm{Pt}$ metals have restricted its application for industrial hydrogen production. Thus, synthesis of a catalyst composed of earthabundance, eco-friendly, and inexpensive elements is essential. Over the past 2 decades, TMCs $\mathrm{MX}_{2}(\mathrm{M}=\mathrm{Mo}, \mathrm{W}, \mathrm{Co}, \mathrm{Ni}$, etc.; $\mathrm{X}=\mathrm{S}$, Se, etc.) have been widely used in electrochemical devices. For example, $\mathrm{MoS}_{2},{ }^{8-10} \mathrm{MoSe}_{2},{ }^{11,12} \mathrm{WS}_{2},{ }^{13,14}$ $\mathrm{CoS}_{2}{ }^{15-19}$ and other catalysts, ${ }^{20-23}$ among which is cobalt pyrite $\left(\mathrm{CoS}_{2}, \mathrm{CoSe}_{2}\right)$, a typical pyrite-type transition metal dichalcogenide, ${ }^{24-30}$ have already been widely used in the field of electrochemistry due to their unique advantages. Meanwhile, the properties of electrochemical devices are closely related to the structure of materials. Therefore, in recent years, scientists have been trying to develop new techniques for synthesizing different structures such as nanoparticles, ${ }^{31}$ nanosheets, ${ }^{32-34}$ nanocrystals, ${ }^{35}$ nanoboxes, ${ }^{36,37}$ nanowires, ${ }^{38}$ and so on. Nonetheless, the performance of pure $\mathrm{CoS}_{2}$ is still insufficient due to lack of active sites and low conductivity. For this reason, it is quite important to adopt a novel strategy to develop electrochemical devices with high-efficiency, superstability, and superior electrochemical performance.

Previous studies have shown that moderate doping can effectively improve the electrochemical catalytic activities, e.g., $\mathrm{N},{ }^{39-45} \mathrm{P},{ }^{46-50} \mathrm{Ni}^{51} \mathrm{Fe},{ }^{52,53} \mathrm{Al},{ }^{54} \mathrm{Se},{ }^{55} \mathrm{Mn},{ }^{56}$ and so on. Therein, the performances of selenide products are much better than those of other products (e.g., sulfur), which may be ascribed to the following reasons: (i) the Se atom has larger electronegativity than the $S$ atom, and the $S e$ atom can substitute the $S$ atom during a high temperature reaction process; (ii) Se (compared to $S$ ) forms a new bond with another element, which causes the lattice spacing to change, facilitating electron conduction at the solution interface, and finally improves the catalytic performance. Therefore, selenium doping is one of the most important means to improve

Received: June 9, 2021

Accepted: July 23, 2021

Published: September 2, 2021 
Scheme 1. Schematic Diagram of Preparation Procedures of Different Samples

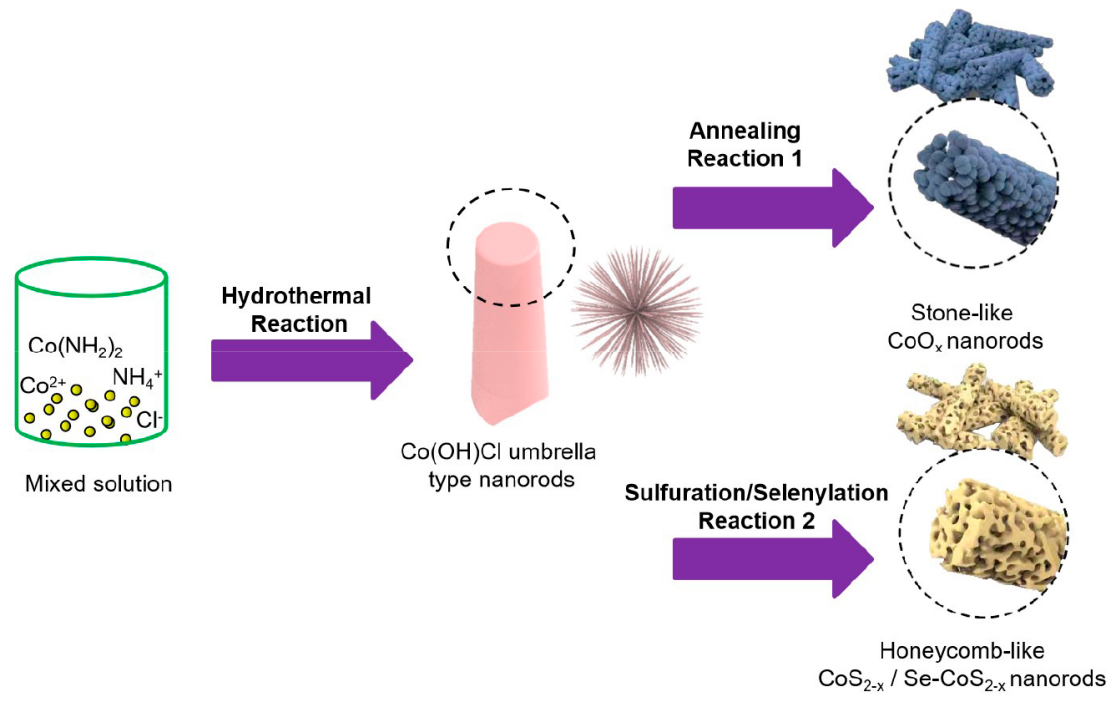

performances of electrochemical catalytic devices. However, as far as we know, the Se dopants are rarely reported, possibly attributed to their uncontrollable preparation process and relatively high cost.

In this work, the porous-like $\mathrm{Se}-\mathrm{CoS}_{2-x}$ nanorod is successfully synthesized via a simple two-step method. The first step is to synthesize umbrella-type $\mathrm{Co}(\mathrm{OH}) \mathrm{Cl}$ nanorods $(\mathrm{Co}(\mathrm{OH}) \mathrm{Cl} \mathrm{UNs})$ as precursor by low temperature hydrothermal reaction. The second step is sulfuration/selenylation at $400{ }^{\circ} \mathrm{C}$ for $1 \mathrm{~h}$. Specific reaction processes are as follows:

$$
\begin{aligned}
& \mathrm{Co}^{2+}+\mathrm{Cl}^{-} \rightarrow \mathrm{CoCl}^{+} \\
& \mathrm{CO}\left(\mathrm{NH}_{2}\right)_{2}+3 \mathrm{H}_{2} \mathrm{O} \rightarrow 2 \mathrm{NH}_{4}^{+}+2 \mathrm{OH}^{-}+\mathrm{CO}_{2} \\
& \mathrm{CoCl}^{+}+\mathrm{OH}^{-} \rightarrow \mathrm{Co}(\mathrm{OH}) \mathrm{Cl} \\
& \mathrm{Co}+(2-x) \mathrm{S} \rightarrow \mathrm{CoS}_{2-x} \\
& \mathrm{Co}+(2-x) \mathrm{S}+y \mathrm{Se} \rightarrow \mathrm{CoS}_{2-x} \mathrm{Se}_{y}
\end{aligned}
$$

The result indicates that the $\mathrm{Se}-\mathrm{CoS}_{2-x}$ catalyst effectively improves the speed of electron transfer, showing much better electrocatalytic performance than that of $\mathrm{CoO}_{x}$ and $\mathrm{CoS}_{2-x}$ catalysts.

\section{RESULTS AND DISCUSSION}

The fabrication of Se doped $\mathrm{CoS}_{2-x}$ electrodes is schematically depicted in Scheme 1. The electrodes are prepared via a sequential two-step approach: (i) $\mathrm{Co}(\mathrm{OH}) \mathrm{Cl}$ UNs are synthesized through a simple hydrothermal growth process; (ii -1$) \mathrm{CoO}_{x}$ electrode is obtained by calcination of the $\mathrm{Co}(\mathrm{OH}) \mathrm{Cl}$ UNs precursor; (ii ${ }_{-2}$ ) $\mathrm{CoS}_{2-x}$ electrode is obtained by low-temperature sulfuration of the $\mathrm{Co}(\mathrm{OH}) \mathrm{Cl} \mathrm{UNs}$ precursor; (ii ${ }_{-3}$ ) $\mathrm{Se}-\mathrm{CoS}_{2-x}$ electrode is obtained by lowtemperature hybrid sulfuration-selenylation of the $\mathrm{Co}(\mathrm{OH}) \mathrm{Cl}$ precursor.

The formation of the product $\left(\mathrm{CoO}_{x}\right)$ may derive from the excessive decomposition of the $\mathrm{Co}(\mathrm{OH}) \mathrm{Cl}$ precursor during the reaction process. Figure $1 \mathrm{a}-\mathrm{f}$ and Figure $\mathrm{S} 1$ present the SEM images of the $\mathrm{CoO}_{x}$ nanorods with the annealing temperature $400{ }^{\circ} \mathrm{C}$. As shown in parts a and b of Figure 1, $\mathrm{CoO}_{x}$ exhibits a stone-like nanorods structure, with diameter of
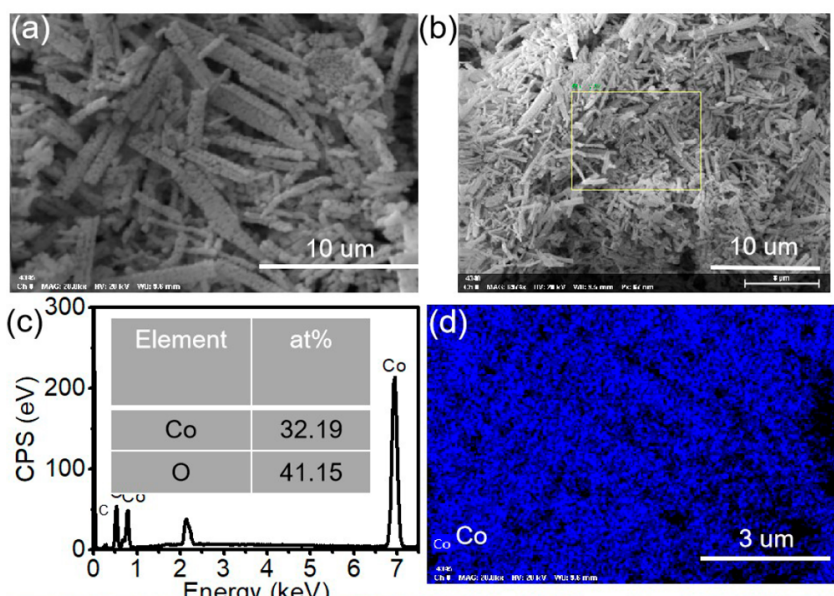

(d)
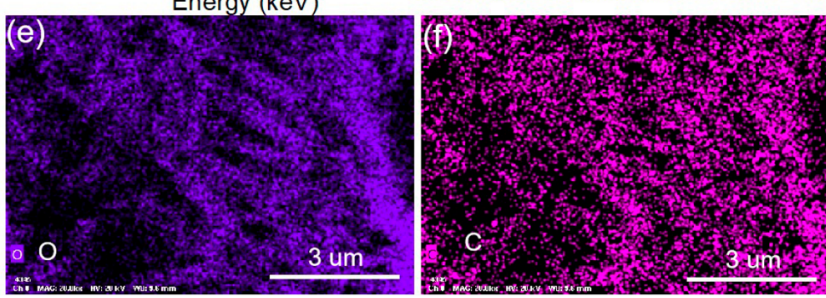

Figure 1. (a) SEM images of the $\mathrm{CoO}_{x}$ nanorods; (b) SEM images of the $\mathrm{CoO}_{x}$ nanorods in other regions; (c) EDX spectrum of the $\mathrm{CoO}_{x}$ nanorods, and elemental mapping of (d) Co, (e) O, and (f) C.

about $200-500 \mathrm{~nm}$ and a length of about $2-10 \mu \mathrm{m}$. Figure $1 \mathrm{c}$ reveals the energy dispersive X-ray (EDX) spectrum of the annealing product, where the ratio of $\mathrm{Co}$ to $\mathrm{O}$ is about 1:1.28, confirming the existence of $\mathrm{CoO}_{x}(x=1.28)$. Distribution of different elements in the $\mathrm{CoO}_{x}$ nanorods is analyzed through elemental mapping. Uniform distribution of $\mathrm{Co}, \mathrm{O}$, and $\mathrm{C}$ elements can be observed in the product, as illustrated in Figure $1 d-f$.

Parts $\mathrm{a}$ and $\mathrm{b}$ of Figure 2 are SEM images of the $\operatorname{CoS}_{2-x}$ electrode, showing $2-10 \mu \mathrm{m}$ porous-rod-like structure stacked by nanoparticles, with some gaps exist between blocks and blocks. The EDX spectrum in Figure $2 \mathrm{c}$ reveals an atomic ratio of Co to $S$ less than 1:2, namely $\operatorname{CoS}_{2-x}$, confirming that some $\mathrm{Co}-\mathrm{S}$ bonds in the product may break off or some sulfur 

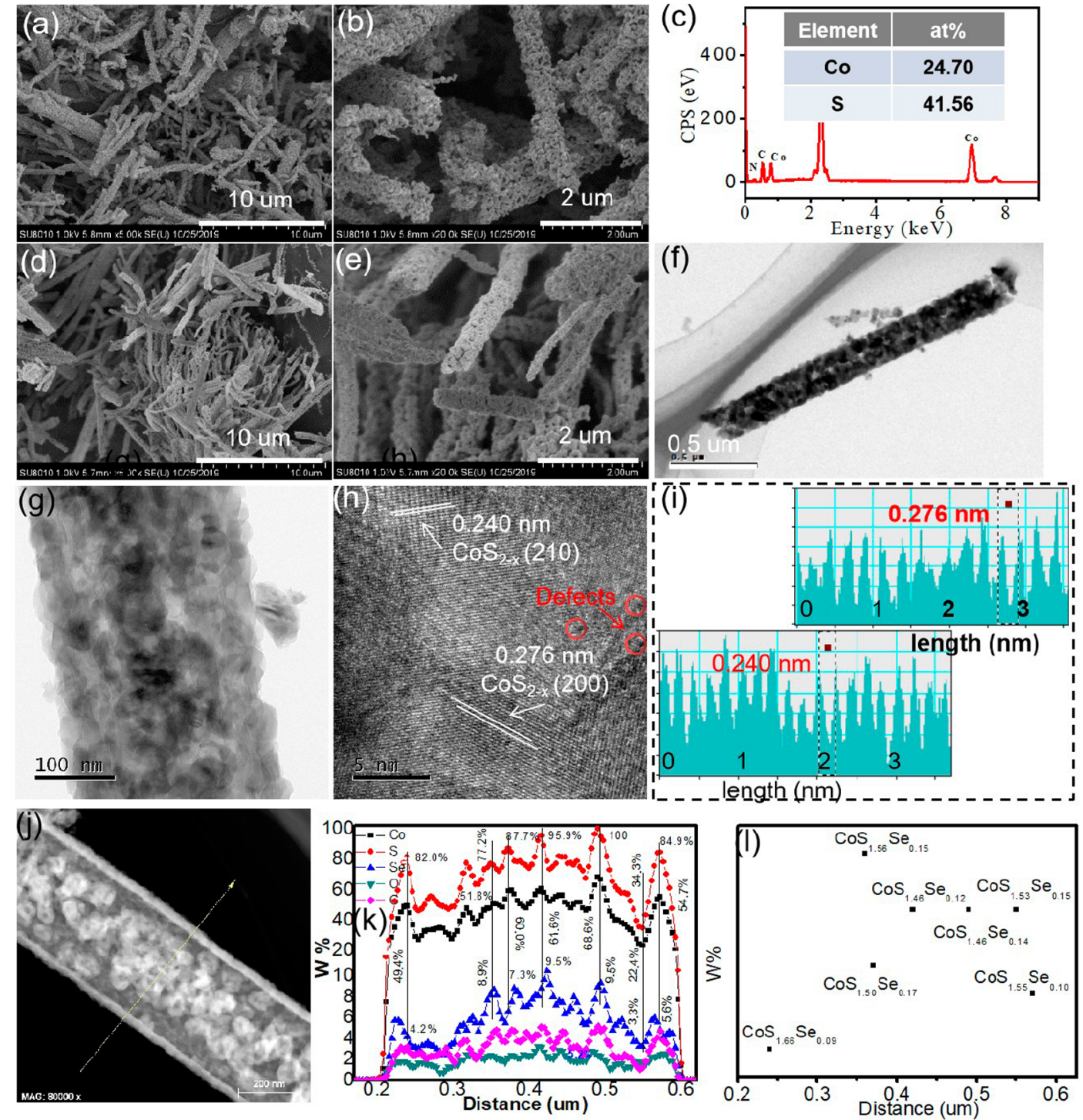

Figure 2. (a, b) SEM images, (c) EDX spectrum of the $\operatorname{CoS}_{2-x}$ sample; (d, e) FESEM, (f) TEM, (g, h) HRTEM images of the Se-CoS $2-x$ sample; (i) insert figure of HRTEM; (j-1) EDS line scan mapping of the $\mathrm{Se}-\mathrm{CoS}_{2-x}$ sample.

vacancy is formed, ${ }^{39}$ as later explained in Figure 3. Similar to the $\mathrm{CoS}_{2-x}$ electrode, SEM images of $\mathrm{Se}-\mathrm{CoS}_{2-x}$ electrode as shown in parts $\mathrm{d}$ and e of Figure 2 also display a porous-rodlike structure, with diameter of about 200-500 nm and length of about $2-10 \mu \mathrm{m}$. As reference, the precursor $\mathrm{Co}(\mathrm{OH}) \mathrm{Cl}$ exhibits umbrella type nanorods structure, with a diameter of about $200-500 \mathrm{~nm}$ and a length of about $2-10 \mu \mathrm{m}$ (Figure $\mathrm{S} 2)$. For the microstructure of the $\mathrm{Se}-\mathrm{CoS}_{2-x}$, transmission electron microscopy (TEM) images are obtained as shown in Figure $2 \mathrm{f}-\mathrm{h}$. The TEM images in parts $\mathrm{f}$ and $\mathrm{g}$ of Figure 2 show that the $\mathrm{Se}-\mathrm{CoS}_{2-x}$ catalyst is about $2 \mu \mathrm{m}$ in length and about $200 \mathrm{~nm}$ in diameter. The high-resolution transmission electron microscopy (HRTEM) image (Figure $2 \mathrm{~h}$ ) reveals that the interplanar spacing of $\mathrm{Se}-\mathrm{CoS}_{2-x}$ catalysts is 0.240 and $0.276 \mathrm{~nm}$, corresponding to the $\left(\begin{array}{lll}2 & 1 & 0\end{array}\right)$ and $\left(\begin{array}{lll}2 & 0 & 0\end{array}\right)$ planes of $\mathrm{CoS}_{2-x}$. In addition, no interfacial spacing of $\mathrm{CoSe}_{2}$ is detected from HRTEM, indicating that Se has been successfully doped into $\mathrm{CoS}_{2-x}$. Figure $2 \mathrm{j}-1$ and Figure S3 show EDS line scan mapping results of the $\mathrm{Se}-\mathrm{CoS}_{2-x}$ nanorod. From the selected points, the atomic number ratio of $\mathrm{Co}$ and $\mathrm{S}$ fluctuates around $1: 1.5$, which may be caused by the sulfur vacancy or the interstitial doping of selenium in the process of sulfuration or selenization.

Formation of $\mathrm{CoS}_{2-x}$ and $\mathrm{Se}-\mathrm{CoS}_{2-x}$ polyporous nanorods may be attributed to the defects, interstitial doping or atomic bond breaking during the sulfuration/selenization process (Figure 3). As shown in Figure 3a, the precursor $\mathrm{Co}(\mathrm{OH}) \mathrm{Cl}$ first forms $\mathrm{CoS}_{2}$ during the sulfuration process at high temperature. Then sulfur vacancy or sulfur interstitially doping is generated as the reaction goes on, finally forming $\operatorname{CoS}_{2-x}$. Similarly, as shown in Figure $3 b$, in the process of high temperature sulfuration/selenization, the precursor $\mathrm{Co}(\mathrm{OH}) \mathrm{Cl}$ is easy to form $\mathrm{Se}-\mathrm{CoS}_{2-x}$ through random selenium doping (may be interstitial doping or in situ substitution). And sulfur vacancy or sulfur interstitially doping will be generated soon, leading to the formation of $\mathrm{Se}-\mathrm{CoS}_{2-x}$. According to the above analysis and Figure $3 c$, the formation mechanism can be explained based on the different reaction rates of $\mathrm{Co}^{2+}, \mathrm{OH}^{-}$, $\mathrm{S}$, and Se: According to the molecular dynamics principle, the $\mathrm{Co}^{2+}$ peak makes it easy to form $\mathrm{CoS}_{2}$ with $\mathrm{S}$ powder. After the formation of $\mathrm{CoS}_{2}$, sulfur vacancy and sulfur bond fracture will occur during the reaction, thus forming $\mathrm{CoS}_{2-x}$. In addition, 
(a)

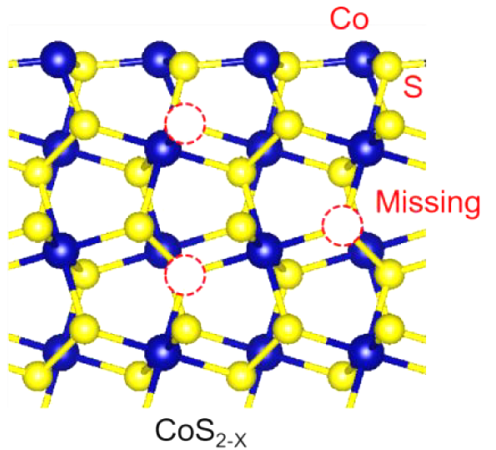

(c)

Co precursors
$\mathrm{V}_{\mathrm{OH}-}=\mathrm{V}_{\mathrm{Co} 2+}>\mathrm{V}_{\mathrm{S} \text { molecule }}$

$\mathrm{CoS}_{2-x}$ nanorod
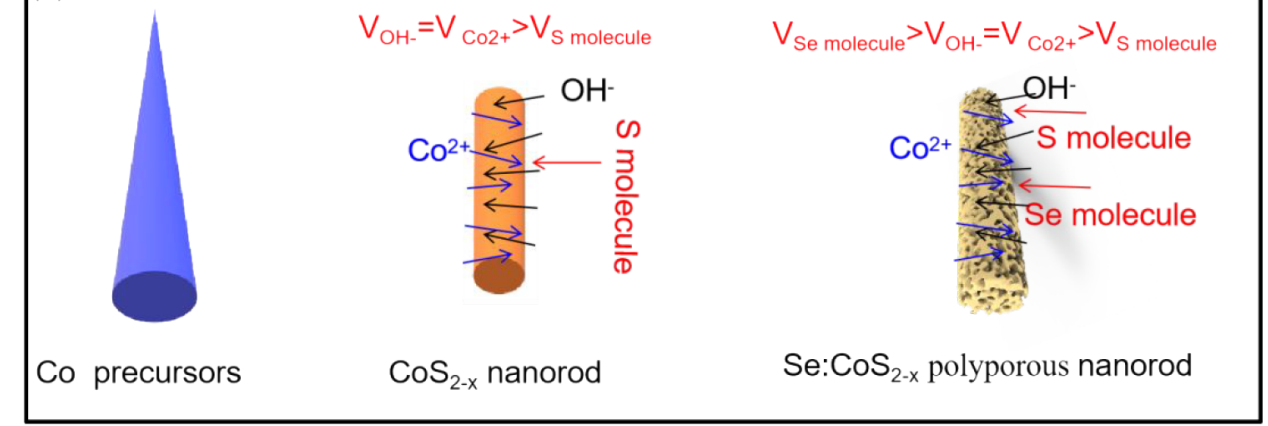

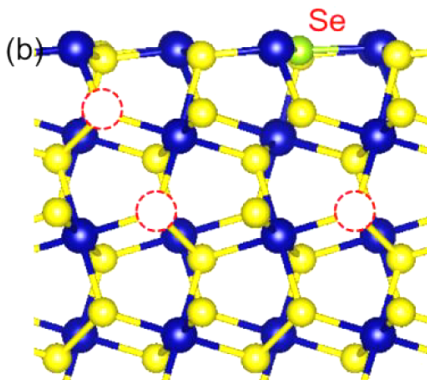

Se:CoS $2-x$

Figure 3. (a, b) Optimized atomic structures of $\mathrm{CoS}_{2-x}$ and $\mathrm{Se}-\mathrm{CoS}_{2-x}$, respectively. (c) Formation mechanism diagram of $\mathrm{CoS}_{2-x}$ nanorod and Se$\mathrm{CoS}_{2-x}$ polyporous nanorod.

selenium also participates in the reaction. At high temperature, selenium atoms are very easy to replace sulfur atoms, or exist in the form of interstitial doping, thus forming $\mathrm{Se}-\mathrm{CoS}_{2-x}$. The increased numbers of active sites due to the effect of selenium doping make important contribution to subsequent electrochemical performance improvement.

The XRD patterns of $\mathrm{CoS}_{2-x}$ and $\mathrm{Se}-\mathrm{CoS}_{2-x}$ catalysts are shown in Figure $4 \mathrm{a}$, where the peaks at $27.2^{\circ}, 32.3^{\circ}, 36.3^{\circ}$, $55.1^{\circ}$, and $62.2^{\circ}$ are indexed to (111), (200), (210), (311), and (321) planes of $\mathrm{CoS}_{2}$ (JCPDS 41-1471), ${ }^{16}$ respectively. Peak value of the obtained product $\mathrm{CoS}_{2-x}$ does not change significantly, indicating that the structure of the product is not damaged under this condition. In addition, slight shift of peaks can be observed after doping Se, with no Se-related new phases, indicating the successful doping of Se element into the structure of $\mathrm{CoS}_{2-x}$. Parts b-f of Figure 4 display XPS survey spectra of $\mathrm{Co}, \mathrm{S}, \mathrm{Se}$, and $\mathrm{O}$ elements, respectively. The Co $2 \mathrm{p}$ can be divided into five peaks as indicated in Figure $4 \mathrm{~b}$, where two obvious peaks at 778.7 and $793.9 \mathrm{eV}$, corresponding to Co $2 \mathrm{p}_{3 / 2}$ and Co $2 \mathrm{p}_{1 / 2}$, are consistent with the previous report. ${ }^{42}$ In addition, The peaks at 778.5 and $793.8 \mathrm{eV}$ may correspond to the $\mathrm{CoO}_{x}$ bonding of the surface oxide in air, consistent with previous report. ${ }^{26}$ Se doping leads peak shift to higher binding energy for about $0.4 \mathrm{eV}$, implying the formation of new $\mathrm{Co}-\mathrm{Se}$ bonds, and indicating that Se doping effectively modifies the electronic structure of Co. In Figure 4c, peaks located at 55.7 and $54.2 \mathrm{eV}$ are attributed to $\mathrm{Se} 3 \mathrm{~d}_{3 / 2}$ and $\mathrm{Se} 3 \mathrm{~d}_{5 / 2}$, respectively, close to the previously reported values of $\mathrm{Se}$ doped $\mathrm{CoS}_{2} \cdot{ }^{53}$ And the broad peak located at $59.7 \mathrm{eV}$ corresponds to the surface oxidation of the Se edges. ${ }^{26}$ Highresolution spectra of $S 2 p$ shown in Figure $4 \mathrm{~d}$ can be decomposed into three peaks, locating at 162.8 and $163.9 \mathrm{eV}$, assigned to $S 2 p_{3 / 2}$ and $S 2 p_{1 / 2}$, respectively, and locating at $168.9 \mathrm{eV}$, assigned to $\mathrm{S}$ surface oxide contamination in $\mathrm{Se}-$ $\mathrm{CoS}_{2-x}$. As shown in Figure 4f, elements Co, S, Se, and O exist in a wide spectrum of $50-800 \mathrm{eV}$, where the detected $\mathrm{O}$ element by XPS may mainly attribute to the absorbed oxygen or hydroxyl group or adsorbed water in the samples. (Figure 4e). ${ }^{32}$ The XPS results confirm that Se doping significantly influence the chemical state of Co and $S$.

In order to discuss the function of Se dopants on the HER process, a series of electrochemical hydrogen evolution experiment are carried out in $0.5 \mathrm{M} \mathrm{H}_{2} \mathrm{SO}_{4}$ solution using a three-electrode system. Specific reaction processes are as follows.

HER in acidic electrolyte gives ${ }^{52}$

$$
\begin{aligned}
& \text { Volmer process: } \mathrm{H}_{3} \mathrm{O}^{+}+\mathrm{X}+\mathrm{e}^{-} \mathrm{X}-\mathrm{H}_{\mathrm{ads}}+\mathrm{H}_{2} \mathrm{O} \\
& \text { Heyrovsky process: } \mathrm{X}-\mathrm{H}_{\mathrm{ads}}+\mathrm{H}_{3} \mathrm{O}^{+}+\mathrm{e}^{-} \mathrm{H}_{2}+\mathrm{X}+\mathrm{H}_{2} \mathrm{O}
\end{aligned}
$$

Tafel process: $2 \mathrm{X}-\mathrm{H}_{\mathrm{ads}} 2 \mathrm{X}+\mathrm{H}_{2}$

(*X stands for the surface active site, $\mathrm{H}_{\mathrm{ads}}$ stands for the adsorbed hydrogen).

The LSV curve is an important measurement index in electrochemical reaction. Results of LSV measurements, as shown in parts $\mathrm{a}$ and $\mathrm{b}$ of Figure 5, reveal that $\mathrm{Se}-\mathrm{CoS}_{2-x}$ electrode performs the best catalytic activities among all catalysts. Its overpotential of only $\sim 260 \mathrm{mV}$ (under the current density of $10 \mathrm{~mA} \mathrm{~cm}^{-2}$ ) is far lower than that of the $\mathrm{CoS}_{2-x}$ electrode $(500 \mathrm{mV})$ and $\mathrm{CoO}_{x}(>500 \mathrm{mV})$. In all samples, it is obvious that the overpotential value of $\mathrm{CoO}_{x}$ is the largest, indicating that the sulfuration or selenization product can provide more active sites. The corresponding Tafel slope is then calculated, as shown in parts $\mathrm{c}$ and $\mathrm{d}$ of Figure 5, via the Tafel formula $y=m+n \log k$ (where $y$ stands for the overpotential, $m$ stands for the Tafel slope, $n$ stands for the intercept, and $k$ stands for the current density). The calculated slope of $\mathrm{Se}-\mathrm{CoS}_{2-x}$ electrode is $89.9 \mathrm{mV} \mathrm{dec}^{-1}$, implying faster 

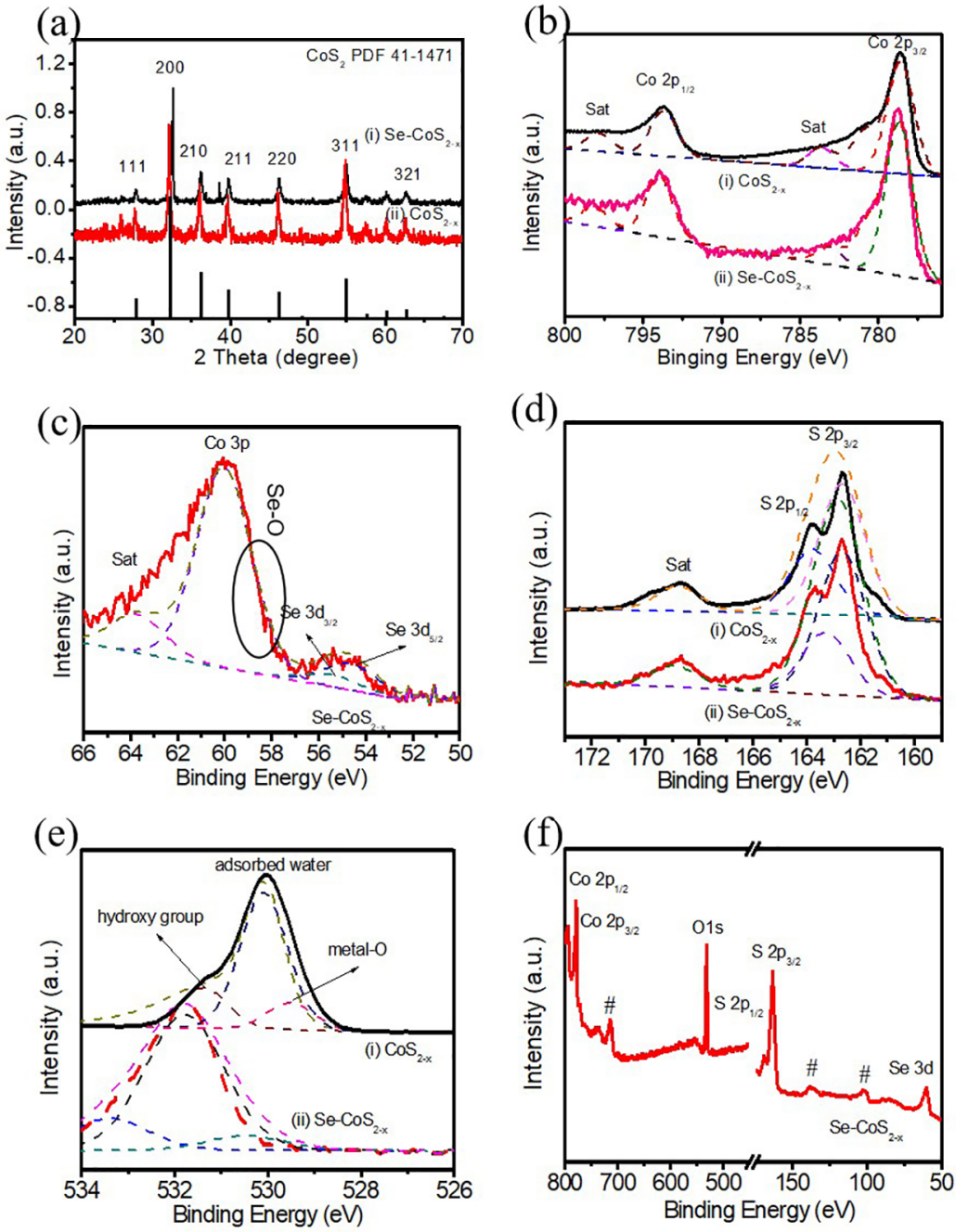

Figure 4. (a) XRD patterns of $\mathrm{CoS}_{2-x}$ and $\mathrm{Se}-\mathrm{CoS}_{2-x}$ with standard peaks of $\mathrm{CoS}_{2}$ listed. (b-f) XPS survey spectra of $\mathrm{CoS}_{2-x}$ and $\mathrm{Se}-\mathrm{CoS} \mathrm{S}_{2-x}$, $\mathrm{Co}$ $2 \mathrm{p}$, Se $3 \mathrm{~d}, \mathrm{~S} 2 \mathrm{p}$, and $\mathrm{O} 1 \mathrm{~s}$, respectively.

proton transfer kinetics, which is conducive to the rapid progress of HER.

In addition, electrochemical impedance spectroscopy is applied for the $\mathrm{CoO}_{x}, \mathrm{CoS}_{2-x}, \mathrm{Se}-\mathrm{CoS}_{2-x}$ electrodes, respectively, as presented in Figure 5e and Figure S3. The circuit in Figure 5e can be used to simulate the resistance in HER, which may be related to the interface properties of the electrolyte. Charge transfer resistance $\left(R_{\mathrm{ct}}\right)$ value of prepared catalysts can be subsequently derived according to the diameter of the Nyquist plots in Figure 5e and Figure S4, where $R_{\mathrm{ct}}$ of $\mathrm{Se}-\mathrm{CoS}_{2-x}$ electrode $(78.9 \Omega)$ is much smaller than that of $\mathrm{CoO}_{x}(\sim 1190 \Omega)$ and $\operatorname{CoS}_{2-x}(\sim 300 \Omega)$, reflecting faster electrocatalytic kinetics and reaction rate. The stability test result (Figure 5f) indicates that the as-prepared electrode material has excellent stability, which can almost maintain its current density even after 2000 cycles durability test.

The $C_{\mathrm{dl}}$ value is calculated to evaluate the electrochemical active surface area (ECSA) of the catalysts, ${ }^{46}$ as shown in parts $\mathrm{a}$ and $\mathrm{b}$ of Figure 6 and Figure S4. The $C_{\mathrm{dl}}$ value of the Se$\mathrm{CoS}_{2-x}$ electrode is calculated to be $2.66 \mathrm{mF} \mathrm{cm}^{-2}$, far more than that for $\mathrm{CoS}_{2}\left(\sim 0.49 \mathrm{mF} \mathrm{cm}{ }^{-2}\right)$, suggesting that Se$\mathrm{CoS}_{2-x}$ has more exposed active sites and defects than $\mathrm{CoS}_{2-x}$, which can explain the enhancement of the HER activity after Se doping. Herein, all of the as-prepared samples possess a similar nanorod morphology, and the greatly improved $C_{\mathrm{dl}}$ results of $\mathrm{Se}-\mathrm{CoS}_{2-x}$ may be ascribed to an increase in the active sites arising from its polyporous-rod-like structure and Se doping factors. Parts $\mathrm{c}$ and $\mathrm{d}$ of Figure 6 illustrate CP curves of the $\mathrm{Se}-\mathrm{CoS}_{2-x}$ electrode under varying overpotential. With increasing overpotential, the current density of the $\mathrm{Se}-\mathrm{CoS}_{2-x}$ electrode rises accordingly and stabilizes soon, indicating outstanding mass transfer performance and mechanical stability of the $\mathrm{Se}-\mathrm{CoS}_{2-x}$ electrode under acidic conditions.

The LSV curve in Figure 7a demonstrates the excellent HER and OER characteristics of $\mathrm{Se}-\mathrm{CoS}_{2-x}$ catalysts under alkaline conditions. As shown in Figure $7 \mathrm{~b}$, the current density remains unchanged at a bias voltage of $-0.5 \mathrm{~V}$, manifesting strong longterm durability of the $\mathrm{Se}-\mathrm{CoS}_{2-x}$ catalyst for HER. parts $\mathrm{c}$ and $\mathrm{d}$ of Figure 7 illustrate $\mathrm{CP}$ curves of the $\mathrm{Se}-\mathrm{CoS}_{2-x}$ under varying overpotentials. Upon increasing the overpotential, the current densities of the $\mathrm{Se}-\mathrm{CoS}_{2-x}$ electrode rise and soon stabilize. The results indicate that $\mathrm{Se}-\mathrm{CoS}_{2-x}$ electrode has outstanding mass transfer performance and mechanical stability under alkaline condition.

The relative effective surface area is assessed to evaluate the catalytic performance by comparing the above values of $\mathrm{C}_{\mathrm{dl}}$. Table 1 shows that the addition of Se element into $\mathrm{CoS}_{2-x}$ material can effectively increase chemical specific surface area, 
(a)

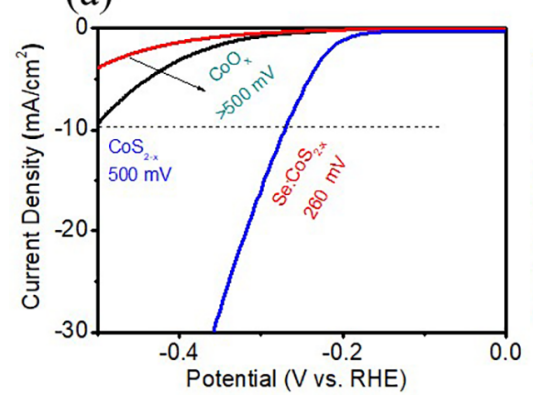

(c)

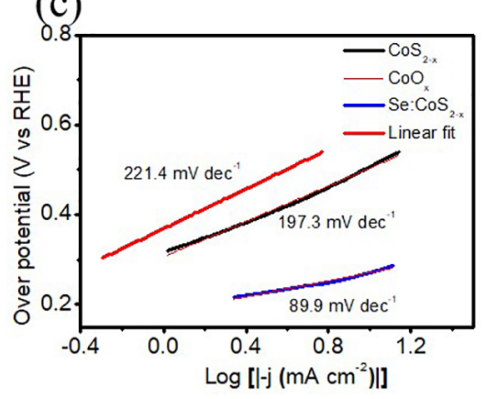

(e)

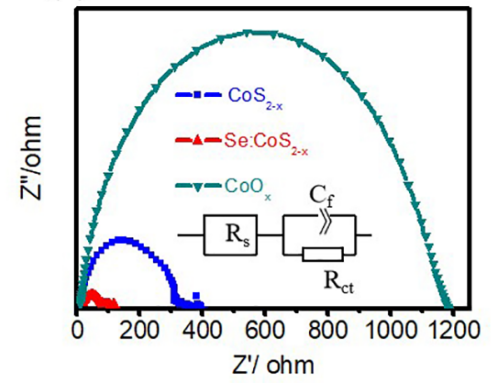

(b)

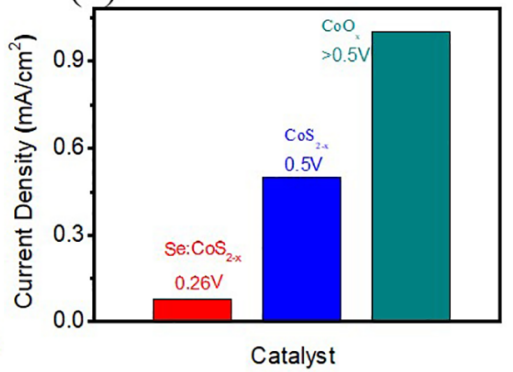

(d)
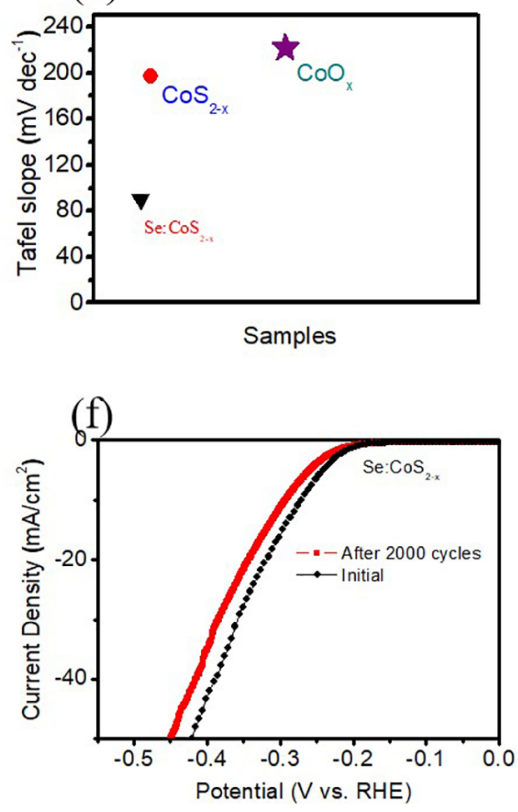

Figure 5. (a) LSV curves of $\mathrm{CoO}_{x}, \mathrm{CoS}_{2-x}$ and $\mathrm{Se}-\mathrm{CoS}_{2-x}$ at a scan rate of $5 \mathrm{mV} \mathrm{s}^{-1}$ in $0.5 \mathrm{M} \mathrm{H}_{2} \mathrm{SO}_{4}$. (b) Summary of the overpotential at $\mathrm{j}=10$ $\mathrm{mA} \mathrm{cm}$ of prepared catalysts. (c) Corresponding Tafel slope of all catalysts. (d) Tafel slope diagram of different catalysts. (e) EIS Nyquist plots of $\mathrm{CoO}_{x}, \mathrm{CoS}_{2-x}$ and $\mathrm{Se}-\mathrm{CoS}_{2-x}$ at $0.8 \mathrm{~V}$. (f) Initial polarization curve of the $\mathrm{Se}-\mathrm{CoS}_{2-x}$ electrode and after 2000 cycles.
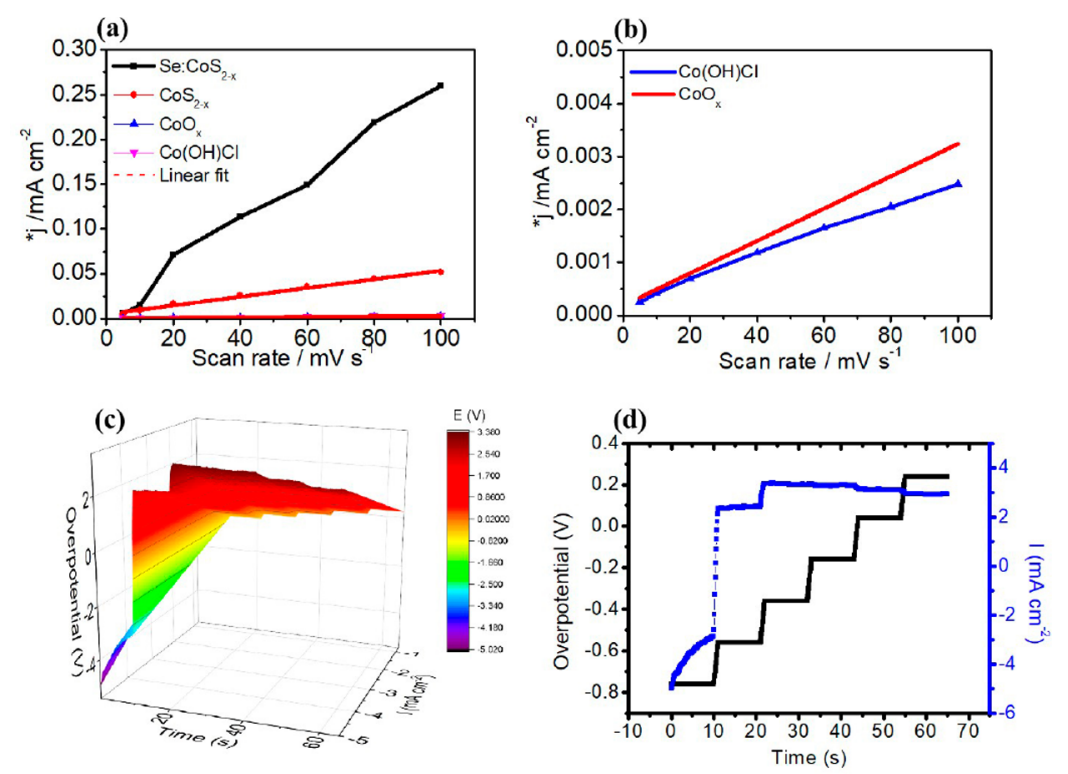

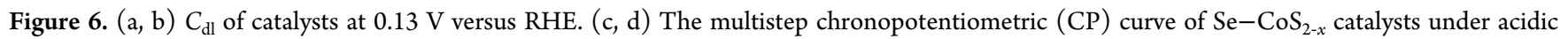
conditions. 
(a)

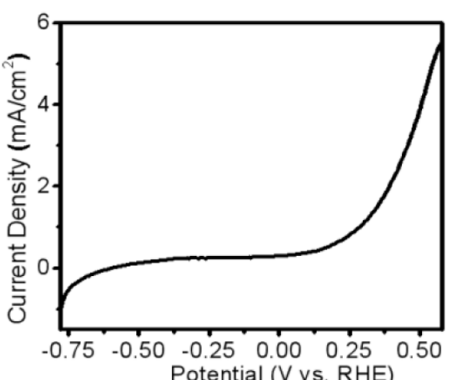

(c)

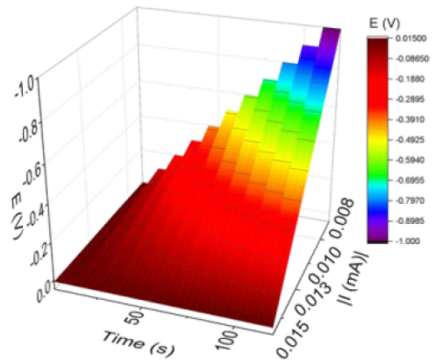

(b)

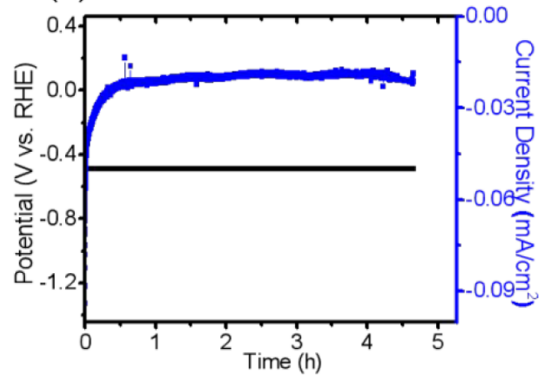

(d)

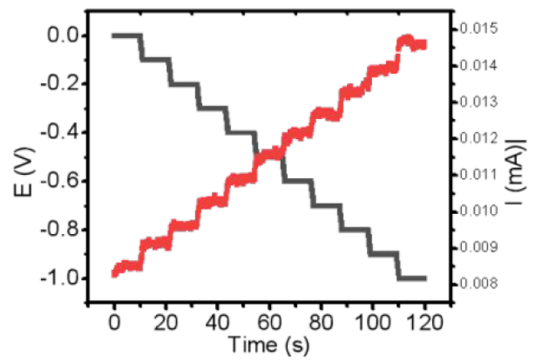

Figure 7. (a) LSV curve of $\mathrm{Se}-\mathrm{CoS}_{2-x}$ with scan rate of $1 \mathrm{mV} \mathrm{s}^{-1}$ in $1 \mathrm{M} \mathrm{KOH}$. (b) Time-dependent current density of Se-CoS $\mathrm{C}_{2-x}$ catalysts. (c, d) Multistep chronopotentiometric curves of $\mathrm{Se}-\mathrm{CoS}_{2-x}$ catalysts under alkaline conditions.

Table 1. Comparison Table of HER Performances of $\mathrm{CoS}_{2-x}$ and $\mathrm{Se}-\mathrm{CoS}_{2-x}$ Samples

$\begin{array}{lrccr}\text { electrodes } & \eta / \mathrm{mV} & \text { Tafel slope } / \mathrm{mV} \mathrm{dec}^{-1} & C_{\mathrm{dl}}{ }^{a} / \mathrm{mF} \mathrm{cm}^{-2} & R_{\mathrm{ct}}{ }^{b} / \Omega \\ \mathrm{Pt} / \mathrm{C} & 29 & 29.03 & - & 29.3 \\ \mathrm{Se}-\mathrm{CoS}_{2-x} & 260 & 89.9 & 2.66 & 78.9 \\ \mathrm{CoS}_{2-x} & 500 & 197.3 & 0.4 & 316.2 \\ \mathrm{CoO}_{x} & >500 & 221.4 & 0.03 & 1190\end{array}$

${ }^{a}$ Double-layer $\left(C_{\mathrm{dl}}\right) \cdot{ }^{b}$ Charge transfer $\left(R_{\mathrm{ct}}\right)$.

leading to better catalytic performance. From the chart below, conclusions can be drawn that (i) sulfur and selenium play significant roles in the HER process. Higher electrocatalytic activity of $\mathrm{Se}-\mathrm{CoS}_{2-x}$ electrode indicates that the contribution of combined $\mathrm{Co}-\mathrm{Se}-\mathrm{S}$ is higher than sole sulfur during the reaction process. (ii) When Se element is doped into the $\mathrm{CoS}_{2-x}$ crystal, $\mathrm{Se}^{2-}$ will replace the part position of $\mathrm{S}^{2-}$, leading to wider crystal surface spacing between $\mathrm{Co}-\mathrm{S}-\mathrm{Se}$ bonds, which is conducive to the transfer of catalyst at the interface.

In order to better investigate the effects of Se doping in $\mathrm{CoS}_{2}$, geometric and electronic structures of the system are calculated via density functional theory (DFT). Parts a and $b$ of Figure 8 display the crystal structure models of pristine $\mathrm{CoS}_{2}$ and $\mathrm{Se}-\mathrm{CoS}_{2}$. The introduction of Se leads to the substitution of some $\mathrm{S}$ atoms by Se. Parts c and d of Figure 8 show band structures and density of states (DOS) plots. The almost identical distribution of $\mathrm{CoS}_{2}$ and $\mathrm{Se}-\mathrm{CoS}_{2}$ means that $\mathrm{Se}$ doping can keep the excellent electronic properties of $\mathrm{CoS}_{2}$. Then, two possible sites on $\mathrm{CoS}_{2}$ and $\mathrm{Se}-\mathrm{CoS}_{2}$ have been examined, that is, the Co-site and the S-site. The Bader charge is analyzed to investigate the electron transfer, as shown in Figure $8 \mathrm{e}$. It can be seen that for all the structure, the charge transfer have a similar behavior before and after Se doping for both the Co-site and the S-site, respectively. This means that the mechanism of adsorption has not changed. Free energy difference of $\mathrm{H}\left(\Delta G_{H^{*}}\right)$ is then calculated (Figure $8 \mathrm{f}$ ) to assess the activity of the surfaces. It can be inferred that Co atoms in
$\mathrm{CoS}_{2}$ and Se:CoS 2 are the active sites for HER, since the $\Delta G_{H^{*}}$ of the Co-site is much closer to zero than that of the S-site. The calculated values of the Co-site and the S-site both show reduction after Se doping $\left(0.44\right.$ and $0.86 \mathrm{eV}$ for $\mathrm{CoS}_{2}, 0.39$ and $0.84 \mathrm{eV}$ for Se-doped $\mathrm{CoS}_{2}$. Observing the lower $\Delta G_{H^{*}}$ of the Co-site after doping with $\mathrm{Se}$, it can be deduced that the Se dopant can reduce the HER energy barrier and promote the hydrogen evolution. Considering that the free energy is related to the doping concentration and structure, another Se-doped $\mathrm{CoS}_{2}$ system has been calculated (Figure S8). And it shows a similar Bader charge value and lower free energy value (0.33 $\mathrm{eV}$ for the Co-site and $0.75 \mathrm{eV}$ for the S-site), confirming that the Se dopant can reduce the HER energy barrier and the structure can effect the free energy. This signifies the importance of $\mathrm{Se}$ in $\mathrm{Se}-\mathrm{CoS}_{2}$ and validates its superior electrocatalytic HER activity over $\mathrm{CoS}_{2}$ as obtained experimentally.

\section{CONCLUSIONS}

In summary, the porous $\mathrm{Se}-\mathrm{CoS}_{2-x}$ nanorod is successfully synthesized by a facile two-step method. The as-prepared Se$\mathrm{CoS}_{2-x}$ electrode exhibits much improved catalytic activity, which may be attributed to the reasons as follows: (i) Under a high temperature reaction, the formation of defects in the catalyst caused by Se doping may provide more active sites, thus improving the performance of hydrogen evolution. (ii) The larger electronegativity of Se atom than $S$ atom makes $\mathrm{Co}-\mathrm{Se}$ bond easier to form. (iii) The synergic effects of Se doping and $\mathrm{CoS}_{2}$ catalyst support are obseved. (iv) When Se elements are doped into the $\mathrm{CoS}_{2}$ crystal, $\mathrm{Se}^{2-}$ will partly replace the position of $\mathrm{S}^{2-}$ and the crystal surface spacing between $\mathrm{Co}-\mathrm{S}-\mathrm{Se}$ bonds will be wider, which is conducive to the transfer of catalyst at the interface. In this paper, the Se$\mathrm{CoS}_{2-x}$ catalyst shows excellent HER performance, such as low overpotential $\left(\sim 260 \mathrm{mV}\right.$ for current density of $\left.10 \mathrm{~mA} \mathrm{~cm}{ }^{-2}\right)$, low Tafel slope $\left(89.9 \mathrm{mV} \operatorname{dec}^{-1}\right)$, and outstanding mass transfer property and mechanical robustness. The above results 

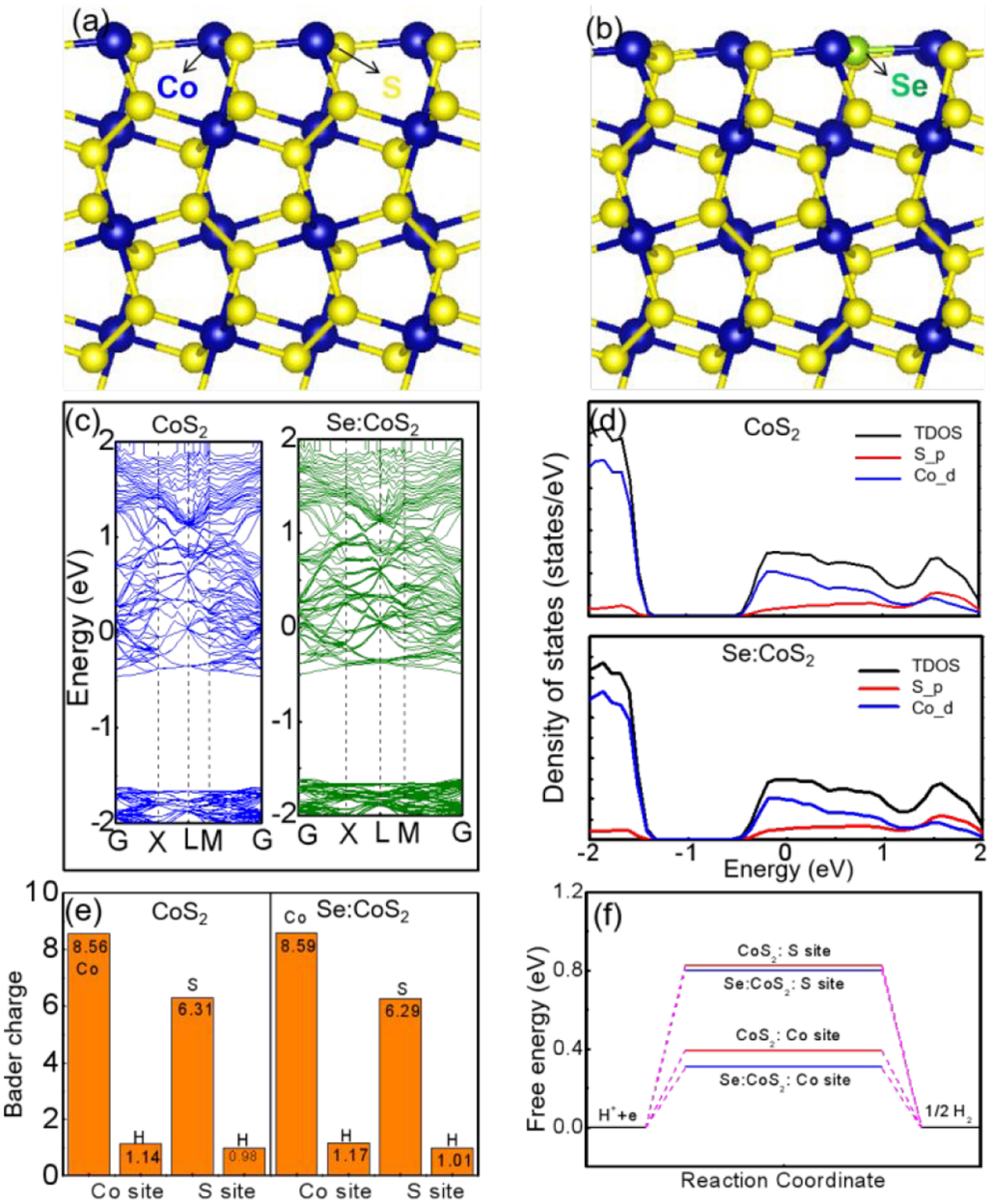

Figure 8. (a, b) Crystal structures of $\mathrm{CoS}_{2}$ and $\mathrm{Se}-\mathrm{CoS}_{2}$, respectively. (c) Electronic band structures of $\mathrm{CoS}_{2}$ and $\mathrm{Se}-\mathrm{CoS}_{2}$. (d) PDOS plots of $\mathrm{CoS}_{2}$ and $\mathrm{Se}-\mathrm{CoS}_{2}$. (e) Calculated Bader charges of Co, S, and $\mathrm{H}$ atoms for $\mathrm{CoS}_{2}$ and $\mathrm{Se}-\mathrm{CoS}_{2}$, respectively. (f) Gibbs free energy of $\mathrm{CoS}_{2}$ and $\mathrm{Se}-\mathrm{CoS}_{2}$ (Co-sites and S-sites).

indicate that doping can greatly enhance the electrochemical catalytic property, and this strategy may be applied to other TMDs materials for energy storage-related applications.

\section{EXPERIMENTAL SECTION}

Synthesis of $\mathrm{Co}(\mathrm{OH}) \mathrm{Cl}$ UNs. Typically, $2 \mathrm{mmol}$ of $\mathrm{CoCl}_{2}$ or $\mathrm{CoCl}_{2} \cdot 6 \mathrm{H}_{2} \mathrm{O}, 7 \mathrm{mmol}$ of $\mathrm{NH}_{4} \mathrm{Cl}$, and $9 \mathrm{mmol}$ of urea were dissolved in deionized water $(35 \mathrm{~mL})$. After being fully stirred, the obtained solution was transferred into a reaction vessel (a $50 \mathrm{~mL}$ autoclave) and then placed in an oven at $140{ }^{\circ} \mathrm{C}$. After $6-12 \mathrm{~h}$ of constant temperature reaction, the autoclave was taken out from the oven for cooling to room temperature. The obtained product was then washed with absolute ethanol for several times, and finally dried overnight under vacuum at 60 ${ }^{\circ} \mathrm{C}$.

Synthesis of $\mathrm{CoO}_{x}$. The annealing process is as follows: $0.01 \mathrm{~g}$ of $\mathrm{Co}(\mathrm{OH}) \mathrm{Cl} \mathrm{UNs}$ samples were located at the hightemperature zone of a tube furnace, the heating zone was heated to $400{ }^{\circ} \mathrm{C}$ with heating rate of $6{ }^{\circ} \mathrm{C} / \mathrm{min}$, the whole process was carried out in $\mathrm{Ar}$ atmosphere, and the final product was obtained after $1 \mathrm{~h}$ of reaction.

Synthesis of Porous Rod-like Cobalt Sulfides. The sulfurization process is described as in our previous work: ${ }^{57}$ First $0.01 \mathrm{~g}$ of $\mathrm{Co}(\mathrm{OH}) \mathrm{Cl}$ UNs sample was located at the hightemperature zone of a tube furnace, and $S$ powder $(0.1 \mathrm{~g})$ was located at the upstream side of the tube furnace, being about $15 \mathrm{~cm}$ apart. The upstream zone was heated to $250{ }^{\circ} \mathrm{C}$ with a heating rate of $6{ }^{\circ} \mathrm{C} / \mathrm{min}$, and the downstream zone was heated to $400{ }^{\circ} \mathrm{C}$ with a heating rate of $10^{\circ} \mathrm{C} / \mathrm{min}$. The whole process was carried out in an $\mathrm{Ar}$ atmosphere, and the final product was obtained after $1 \mathrm{~h}$ reaction.

Synthesis of Porous Rod-like Se-Doped Cobalt Sulfides. The whole process was almost identical as described in the previous procedure of synthesizing cobalt sulfides, except for replacing the $S$ powder $(0.1 \mathrm{~g})$ with a mixture of $S$ powder $(0.08 \mathrm{~g})$ and Se powder $(0.02 \mathrm{~g})$.

Characterization. Field emission scanning electron microscopy (FESEM, SU8010, Hitachi Japan and TESCAN MIRA3) and field emission transmission electron microscopy (FETEM, JEM2100F, $200 \mathrm{kV}$ ) were used to characterize the microstructure and morphologies of samples. The chemical components and elemental state of the samples were detected via X-ray photoelectron spectroscopy (XPS, Escalab 250Xi, Al $\mathrm{K} \alpha$, USA). The crystallite structures of the products were observed by using X-ray diffraction (XRD, Xpert Pro MPD diffractometer, $\mathrm{Cu} \mathrm{K} \alpha$ radiation).

Preparation of Electrode. The electrode was prepared using the method we have reported before. ${ }^{62}$ The dispersion solution composed of $4 \mathrm{mg}$ of sample, $30 \mu \mathrm{L}$ of Nafion solution (5 wt \%), and 1:4 mixed solution of water $(200 \mu \mathrm{L})$ 
and ethanol $(800 \mu \mathrm{L})$, was placed under ultrasonic vibration for about $1 \mathrm{~h}$ to form a homogeneous catalyst ink. Then $5 \mu \mathrm{L}$ of the dispersion solution was loaded onto a working electrode (glassy carbon electrode, diameter $d=3 \mathrm{~mm}$ ). The catalyst was about $0.285 \mathrm{mg} \mathrm{cm}^{-2}$.

Electrochemical Measurement. A three-electrode test system was adopted (working electrode, glassy carbon electrode; reference electrode, $\mathrm{Ag} / \mathrm{AgCl}$ (saturated $\mathrm{KCl}$ ) electrode; and counter electrode, graphite rod). Electrochemical hydrogen evolution performance test of all samples were completed by $\mathrm{CHI} 660 \mathrm{E}$ electrochemical station and ZAHNER pro electrochemical workstation. The Linear sweep voltammetry (LSV) was performed in $0.5 \mathrm{M} \mathrm{H}_{2} \mathrm{SO}_{4}$ solution (pure $\mathrm{N}_{2}$ ). The potential of reversible hydrogen electrode (RHE) was calibrated as $E_{\mathrm{RHE}}=E_{\mathrm{Ag} / \mathrm{AgCl}}+0.217 \mathrm{~V}^{28}$ The HER stability of all catalysts were tested by an amperometric $i-t$ curve with a scan rate of $100 \mathrm{mV} \mathrm{s}^{-1}$. The double-layer capacitances $\left(C_{\mathrm{dl}}\right)$ were estimated by $\mathrm{CV}$ in the range of $0.08-$ $0.19 \mathrm{~V}$ versus RHE region at various scan rates $(5-100 \mathrm{mV}$ $\mathrm{s}^{-1}$ ). The electrochemical impedance spectroscopy (EIS) was tested with an AC voltage of $0.8 \mathrm{~V}$ over the frequencies $0.1-$ $10^{5} \mathrm{~Hz}$.

DFT Calculations. The geometric and electronic structures of systems were calculated via density functional theory (DFT), and implemented in the Vienna ab initio simulation package (VASP). ${ }^{58}$ The interactions between valence electrons and ionic cores were described by the projector-augmented wave (PAW) method, and the electron exchange and correlation were described by generalized gradient approximation (GGA) functional of Perdew, Burke, and Ernzerhof $(\mathrm{PBE}) .{ }^{59}$ In the calculation, the force convergence criterion and energy convergence criterion was set to be $0.01 \mathrm{eV} / \AA$ and $10^{-5} \mathrm{eV}$, respectively. The cutoff energy was set as $450 \mathrm{eV}$. The Monkhorst-Pack grid was set to be $7 \times 7 \times 7$ and $7 \times 7 \times 1$ to the first Brillouin zone for bulk and surface systems, respectively.

\section{ASSOCIATED CONTENT}

\section{SI Supporting Information}

The Supporting Information is available free of charge at https://pubs.acs.org/doi/10.1021/acsomega.1c03019.

SEM images of precursor $\mathrm{Co}(\mathrm{OH}) \mathrm{Cl} \mathrm{UNs}$ and the wide spectrum of $\mathrm{Se}-\mathrm{CoS}_{2-x}$ nanorod (PDF)

\section{AUTHOR INFORMATION}

\section{Corresponding Author}

Zhihong Zhu - College of Advanced Interdisciplinary Studies \& Hunan Provincial Key Laboratory of Novel NanoOptoelectronic Information Materials and Devices, National University of Defense Technology, Changsha 410073, China; ○ orcid.org/0000-0003-3199-9323; Email: zzhwcx@ 163.com

\section{Authors}

Zhengtian Shi - College of Advanced Interdisciplinary Studies \& Hunan Provincial Key Laboratory of Novel NanoOptoelectronic Information Materials and Devices, National University of Defense Technology, Changsha 410073, China Xiangqian Qi - College of Advanced Interdisciplinary Studies \& Hunan Provincial Key Laboratory of Novel NanoOptoelectronic Information Materials and Devices, National University of Defense Technology, Changsha 410073, China
Zhiyuan Zhang - College of Advanced Interdisciplinary Studies \& Hunan Provincial Key Laboratory of Novel NanoOptoelectronic Information Materials and Devices, National University of Defense Technology, Changsha 410073, China

Yingchao Song - College of Advanced Interdisciplinary Studies \& Hunan Provincial Key Laboratory of Novel NanoOptoelectronic Information Materials and Devices, National University of Defense Technology, Changsha 410073, China

Jianfa Zhang - College of Advanced Interdisciplinary Studies \& Hunan Provincial Key Laboratory of Novel NanoOptoelectronic Information Materials and Devices, National University of Defense Technology, Changsha 410073, China; orcid.org/0000-0001-5879-5633

Chucai Guo - College of Advanced Interdisciplinary Studies \& Hunan Provincial Key Laboratory of Novel Nano-

Optoelectronic Information Materials and Devices, National University of Defense Technology, Changsha 410073, China

Complete contact information is available at:

https://pubs.acs.org/10.1021/acsomega.1c03019

\section{Author Contributions}

'Z.S., X.Q., and Z.Zhang contributed equally to this study.

Notes

The authors declare no competing financial interest.

\section{ACKNOWLEDGMENTS}

This work is financially supported by the Natural National Science Foundation of China (NSFC) (11674396).

\section{REFERENCES}

(1) McCollum, D. L.; Jewell, J.; Krey, V.; Bazilian, M.; Fay, M.; Riahi, K. Quantifying uncertainties influencing the long-term impacts of oil prices on energy markets and carbon emissions. Nat. Energy 2016, 1, 77-84.

(2) McFarland, E. Unconventional Chemistry for Unconventional Natural Gas. Science 2012, 338, 340-343.

(3) Jewell, J.; McCollum, D.; Emmerling, J.; Bertram, C.; Gernaat, D. E. H. J.; Krey, V.; Paroussos, L.; Berger, L.; Fragkiadakis, K.; Keppo, I.; Saadi, N.; Tavoni, M.; van Vuuren, D.; Vinichenko, V.; Riahi, K. Limited emission reductions from fuel subsidy removal except in energy-exporting regions. Nature 2018, 554, 229-233.

(4) Qiu, Y.; Liu, W.; Chen, W.; Chen, W.; Zhou, G.; Hsu, P.-C.; Zhang, R.; Liang, Z.; Fan, S.; Zhang, Y.; Cui, Y. Efficient solar-driven water splitting by nanocone $\mathrm{BiVO}_{4}$-perovskite tandem cells. Sci. Adv. 2016, 2, e1501764.

(5) Chong, L.; Wen, J.; Kubal, J.; Sen, F. G.; Zou, J.; Greeley, J.; Chan, M.; Barkholtz, H.; Ding, W.; Liu, D.-J. Ultralow-loading platinum-cobalt fuel cell catalysts derived from imidazolate frameworks. Science 2018, 362, 1276-1281.

(6) Mao, J.; Chen, W.; He, D.; Wan, J.; Pei, J.; Dong, J.; Wang, Y.; An, P.; Jin, Z.; Xing, W.; Tang, H.; Zhuang, Z.; Liang, X.; Huang, Y.; Zhou, G.; Wang, L.; Wang, D.; Li, Y. Design of ultrathin Pt-Mo-Ni nanowire catalysts for ethanol electrooxidation. Sci. Adv. 2017, 3, e1603068.

(7) Wang, L.; Chen, M.-X.; Yan, Q.-Q.; Xu, S.-L.; Chu, S.-Q.; Chen, P.; Lin, Y.; Liang, H.-W. A sulfur-tethering synthesis strategy toward high-loading atomically dispersed noble metal catalysts. Sci. Adv. 2019, 5, eaax6322.

(8) Shi, Z.-T.; Kang, W.; Xu, J.; Sun, Y.-W.; Jiang, M.; Ng, T.-W.; Xue, H.-T.; Yu, D. Y. W.; Zhang, W.; Lee, C.-S. Hierarchical nanotubes assembled from $\mathrm{MoS}_{2}$-carbon monolayer sandwiched superstructure nanosheets for high-performance sodium ion batteries. Nano Energy 2016, 22, 27-37.

(9) Zhang, X.; Grajal, J.; Vazquez-Roy, J. L.; Radhakrishna, U.; Wang, X.; Chern, W.; Zhou, L.; Lin, Y.; Shen, P.-C.; Ji, X.; Ling, X.; 
Zubair, A.; Zhang, Y.; Wang, H.; Dubey, M.; Kong, J.; Dresselhaus, M.; Palacios, T. Two-dimensional $\mathrm{MoS}_{2}$-enabled flexible rectenna for Wi-Fi-band wireless energy harvesting. Nature 2019, 566, 368-372.

(10) Li, H.; Wang, J.; Gao, S.; Chen, Q.; Peng, L.; Liu, K.; Wei, X. Superlubricity between $\mathrm{MoS}_{2}$ Monolayers. Adv. Mater. 2017, 29, 1701474.

(11) Shi, Z.-T.; Kang, W.; Xu, J.; Sun, L.-L.; Wu, C.; Wang, L.; Yu, Y.-Q.; Yu, D. Y. W.; Zhang, W.; Lee, C.-S. In Situ Carbon-Doped $\mathrm{Mo}\left(\mathrm{Se}_{0.85} \mathrm{~S}_{0.15}\right)_{2}$ Hierarchical Nanotubes as Stable Anodes for HighPerformance Sodium-Ion Batteries. Small 2015, 11, 5667-5674.

(12) Kim, S.; Maassen, J.; Lee, J.; Kim, S. M.; Han, G.; Kwon, J.; Hong, S.; Park, J.; Liu, N.; Park, Y. C.; Omkaram, I.; Rhyee, J.-S.; Hong, Y. K.; Yoon, Y. Interstitial Mo-Assisted Photovoltaic Effect in Multilayer $\mathrm{MoSe}_{2}$ Phototransistors. Adv. Mater. 2018, 30, 17055421705550.

(13) Bellani, S.; Wang, F.; Longoni, G.; Najafi, L.; Oropesa-Nuñez, R.; Del Rio Castillo, A. E.; Prato, M.; Zhuang, X.; Pellegrini, V.; Feng, X.; Bonaccorso, F. WS 2 -Graphite Dual-Ion Batteries. Nano Lett. 2018, $18,7155-7164$.

(14) Asadi, M.; Kim, K.; Liu, C.; Addepalli, A. V.; Abbasi, P.; Yasaei, P.; Phillips, P.; Behranginia, A.; Cerrato, J. M.; Haasch, R.; Zapol, P.; Kumar, B.; Klie, R. F.; Abiade, J.; Curtiss, L. A.; Salehi-Khojin, A. Nanostructured transition metal dichalcogenide electrocatalysts for $\mathrm{CO}_{2}$ reduction in ionic liquid. Science 2016, 353, 467.

(15) Yu, L.; Yang, J. F.; Lou, X. W. D. Formation of $\mathrm{CoS}_{2}$ Nanobubble Hollow Prisms for Highly Reversible Lithium Storage. Angew. Chem., Int. Ed. 2016, 55, 13422-13426.

(16) Faber, M. S.; Dziedzic, R.; Lukowski, M. A.; Kaiser, N. S.; Ding, Q.; Jin, S. High-Performance Electrocatalysis Using Metallic Cobalt Pyrite $\left(\mathrm{CoS}_{2}\right)$ Micro-and Nanostructures. J. Am. Chem. Soc. 2014, 136, 10053-10061.

(17) Ai, G.; Hu, Q.; Zhang, L.; Dai, K.; Wang, J.; Xu, Z.; Huang, Y.; Zhang, B.; Li, D.; Zhang, T.; Liu, G.; Mao, W. Investigation of the Nanocrystal $\mathrm{CoS}_{2}$ Embedded in 3D Honeycomb-like Graphitic Carbon with a Synergistic Effect for High-Performance Lithium Sulfur Batteries. ACS Appl. Mater. Interfaces 2019, 11, 33987-33999.

(18) Jin, J.; Zhang, X.; He, T. Self-Assembled $\mathrm{CoS}_{2}$ Nanocrystal Film as an Efficient Counter Electrode for Dye-Sensitized Solar Cells. J. Phys. Chem. C 2014, 118, 24877-24883.

(19) Pan, Y.; Cheng, X.; Gong, L.; Shi, L.; Zhou, T.; Deng, Y.; Zhang, H. Double-Morphology $\mathrm{CoS}_{2}$ Anchored on N-Doped Multichannel Carbon Nanofibers as High-Performance Anode Materials for Na-Ion Batteries. ACS Appl. Mater. Interfaces 2018, 10, 31441-31451.

(20) Huang, L.; Han, B.; Xi, Y.; Forrey, R. C.; Cheng, H. Influence of Charge on the Reactivity of Supported Heterogeneous Transition Metal Catalysts. ACS Catal. 2015, 5, 4592-4597.

(21) Price, S. W. T.; Martin, D. J.; Parsons, A. D.; Sławinski, W. A.; Vamvakeros, A.; Keylock, S. J.; Beale, A. M.; Mosselmans, J. F. W. Chemical imaging of Fischer-Tropsch catalysts under operating conditions. Sci. Adv. 2017, 3, e1602838.

(22) Nazimov, D. A.; Klimov, O. V.; Shaverina, A. V.; Cherepanova, S. V.; Larina, T. V.; Khabibulin, D. F.; Noskov, A. S. The Effect of Transition Alumina $\left(\gamma-, \eta-, \chi-\mathrm{Al}_{2} \mathrm{O}_{3}\right)$ on the Activity and Stability of Chromia/Alumina Catalysts. Energy Technol. 2019, 7, 18007361800743.

(23) Zhang, L.; Wang, T.; Sun, L.; Sun, Y.; Hu, T.; Xu, K.; Ma, F. Hydrothermal synthesis of 3D hierarchical $\mathrm{MoSe}_{2} / \mathrm{NiSe}_{2}$ composite nanowires on carbon fiber paper and their enhanced electrocatalytic activity for the hydrogen evolution reaction. J. Mater. Chem. A 2017, 5, 19752-19759.

(24) Zhang, K.; Park, M.; Zhou, L.; Lee, G.-H.; Li, W.; Kang, Y.-M.; Chen, J. Urchin-Like $\mathrm{CoSe}_{2}$ as a High-Performance Anode Material for Sodium-Ion Batteries. Adv. Funct. Mater. 2016, 26, 6728-6735.

(25) Gao, M.-R.; Cao, X.; Gao, Q.; Xu, Y.-F.; Zheng, Y.-R.; Jiang, J.; $\mathrm{Yu}$, S.-H. Nitrogen-Doped Graphene Supported $\mathrm{CoSe}_{2}$ Nanobelt Composite Catalyst for Efficient Water Oxidation. ACS Nano 2014, 8, 3970-3978.
(26) Gui, Y.; Liu, X.; Dou, Y.; Zhang, L.; Al-Mamun, M.; Jiang, L.; Yin, H.; He, C.-T.; Zhao, H. Manipulating the assembled structure of atomically thin $\mathrm{CoSe}_{2}$ nanomaterials for enhanced water oxidation catalysis. Nano Energy 2019, 57, 371-378.

(27) Yin, H.; Qu, H.-Q.; Liu, Z.; Jiang, R.-Z.; Li, C.; Zhu, M.-Q. Long cycle life and high rate capability of three dimensional $\mathrm{CoSe}_{2}$ grain-attached carbon nanofibers for flexible sodium-ion batteries. Nano Energy 2019, 58, 715-723.

(28) Xia, Z.; Sun, H.; He, X.; Sun, Z.; Lu, C.; Li, J.; Peng, Y.; Dou, S.; Sun, J.; Liu, Z. In situ construction of $\mathrm{CoSe}_{2} @$ vertical-oriented graphene arrays as self-supporting electrodes for sodium-ion capacitors and electrocatalytic oxygen evolution. Nano Energy 2019, 60, 385-393.

(29) Fang, Y.; Yu, X. Y.; Lou, X. W. D. Formation of Hierarchical $\mathrm{Cu}$-Doped $\mathrm{CoSe}_{2}$ Microboxes via Sequential Ion Exchange for HighPerformance Sodium-Ion Batteries. Adv. Mater. 2018, 30, 1706668106673.

(30) Tabassum, H.; Zhi, C.; Hussain, T.; Qiu, T.; Aftab, W.; Zou, R. Encapsulating Trogtalite $\mathrm{CoSe}_{2}$ Nanobuds into BCN Nanotubes as High Storage Capacity Sodium Ion Battery Anodes. Adv. Energy Mater. 2019, 9, 1901778-1901787.

(31) Li, M.; Qian, Y.; Du, J.; Wu, H.; Zhang, L.; Li, G.; Li, K.; Wang, W.; Kang, D. J. CuS Nanosheets Decorated with $\mathrm{CoS}_{2}$ Nanoparticles as an Efficient Electrocatalyst for Enhanced Hydrogen Evolution at All pH Values. ACS Sustainable Chem. Eng. 2019, 7, 14016-14022.

(32) Hou, J.; Zhang, B.; Li, Z.; Cao, S.; Sun, Y.; Wu, Y.; Gao, Z.; Sun, L. Vertically Aligned Oxygenated-CoS $-\mathrm{MoS}_{2}$ Heteronanosheet Architecture from Polyoxometalate for Efficient and Stable Overall Water Splitting. ACS Catal. 2018, 8, 4612-4621.

(33) Han, X.; Wu, X.; Deng, Y.; Liu, J.; Lu, J.; Zhong, C.; Hu, W. Ultrafine Pt Nanoparticle-Decorated Pyrite-Type $\mathrm{CoS}_{2}$ Nanosheet Arrays Coated on Carbon Cloth as a Bifunctional Electrode for Overall Water Splitting. Adv. Energy Mater. 2018, 8, 18009351800946.

(34) Li, Q.; Xing, Z.; Wang, D.; Sun, X.; Yang, X. In Situ Electrochemically Activated CoMn-S@NiO/CC Nanosheets Array for Enhanced Hydrogen Evolution. ACS Catal. 2016, 6, 2797-2801.

(35) Gao, J.; Liang, G.; Zhang, B.; Kuang, Y.; Zhang, X.; Xu, B. FePt@CoS 2 Yolk-Shell Nanocrystals as a Potent Agent to Kill HeLa Cells. J. Am. Chem. Soc. 2007, 129, 1428-1433.

(36) Fang, Y.; Guan, B. Y.; Luan, D.; Lou, X. W. Synthesis of CuS@ $\mathrm{CoS}_{2}$ Double-Shelled Nanoboxes with Enhanced Sodium Storage Properties. Angew. Chem., Int. Ed. 2019, 58, 7739-7743.

(37) Fang, Y.; Guan, B.; Luan, D.; Lou, X. W. D. Elegant Synthesis of CuS@CoS 2 Double-Shelled Nanoboxes with Enhanced Sodium Storage Properties. Angew. Chem. 2019, 131, 7821-7825.

(38) Yan, S.; Wang, K.; Zhou, F.; Lin, S.; Song, H.; Shi, Y.; Yao, J. Ultrafine Co: $\mathrm{FeS}_{2} / \mathrm{CoS}_{2}$ Heterostructure Nanowires for Highly Efficient Hydrogen Evolution Reaction. ACS Appl. Mater. Interfaces 2020, 3, 514-520.

(39) Zhang, J.; Xiao, W.; Xi, P.; Xi, S.; Du, Y.; Gao, D.; Ding, J. Activating and Optimizing Activity of $\mathrm{CoS}_{2}$ for Hydrogen Evolution Reaction through the Synergic Effect of N Dopants and S Vacancies. ACS Energy Lett. 2017, 2, 1022-1028.

(40) He, G.; Zhang, W.; Deng, Y.; Zhong, C.; Hu, W.; Han, X. Engineering Pyrite-Type Bimetallic Ni-Doped $\mathrm{CoS}_{2}$ Nanoneedle Arrays over a Wide Compositional Range for Enhanced Oxygen and Hydrogen Electrocatalysis with Flexible Property. Catalysts 2017, 7, 366-382.

(41) Chen, P.; Zhou, T.; Chen, M.; Tong, Y.; Zhang, N.; Peng, X.; Chu, W.; Wu, X.; Wu, C.; Xie, Y. Enhanced Catalytic Activity in Nitrogen-Anion Modified Metallic Cobalt Disulfide Porous Nanowire Arrays for Hydrogen Evolution. ACS Catal. 2017, 7, 7405-7411.

(42) Guo, L.; Deng, J.; Wang, G.; Hao, Y.; Bi, K.; Wang, X.; Yang, Y. N, P-doped $\mathrm{CoS}_{2}$ Embedded in $\mathrm{TiO}_{2}$ Nanoporous Films for Zn-Air Batteries. Adv. Funct. Mater. 2018, 28, 1804540-1804547.

(43) Pan, Y.; Cheng, X.; Gong, L.; Shi, L.; Zhang, H. Nanoflowerlike $\mathrm{N}$-doped $\mathrm{C} / \mathrm{CoS}_{2}$ as high-performance anode materials for $\mathrm{Na}$ ion batteries. Nanoscale 2018, 10, 20813-20820. 
(44) Hao, J.; Yang, W.; Peng, Z.; Zhang, C.; Huang, Z.; Shi, W. A Nitrogen Doping Method for $\mathrm{CoS}_{2}$ Electrocatalysts with Enhanced Water Oxidation Performance. ACS Catal. 2017, 7, 4214-4220.

(45) Zhang, J.; Xiao, W.; Xi, P.; Xi, S.; Du, Y.; Gao, D.; Ding, J. Activating and Optimizing Activity of $\mathrm{CoS}_{2}$ for Hydrogen Evolution Reaction through the Synergic Effect of N Dopants and S Vacancies. ACS Energy Lett. 2017, 2, 1022-1028.

(46) Chen, C.-J.; Liu, C.-W.; Yang, K.-C.; Yin, L.-C.; Wei, D.-H.; Hu, S.-F.; Liu, R.-S. Amorphous Phosphorus-Doped Cobalt Sulfide Modified on Silicon Pyramids for Efficient Solar Water Reduction. ACS Appl. Mater. Interfaces 2018, 10, 37142-37149.

(47) Zhang, J.; Liu, Y.; Xia, B.; Sun, C.; Liu, Y.; Liu, P.; Gao, D. Facile one-step synthesis of phosphorus-doped $\mathrm{CoS}_{2}$ as efficient electrocatalyst for hydrogen evolution reaction. Electrochim. Acta 2018, 259, 955-961.

(48) Zhang, Y.-Y.; Zhang, X.; Wu, Z.-Y.; Zhang, B.-B.; Zhang, Y.; Jiang, W.-J.; Yang, Y.-G.; Kong, Q.-H.; Hu, J.-S. Fe/P Dual Doping Boosts the Activity and Durability of $\mathrm{CoS}_{2}$ Polycrystalline Nanowires for Hydrogen Evolution. J. Mater. Chem. A 2019, 7, 5195-5200.

(49) Ouyang, C.; Wang, X.; Wang, S. Phosphorus-Doped $\mathrm{CoS}_{2}$ Nanosheet Arrays as Ultra-efficient Electrocatalysts for Hydrogen Evolution Reaction. Chem. Commun. 2015, 51, 14160-14163.

(50) Zhang, J.; Liu, Y.; Xia, B.; Sun, C.; Liu, Y.; Liu, P.; Gao, D. Facile one-step synthesis of phosphorus-doped $\mathrm{CoS}_{2}$ as efficient electrocatalyst for hydrogen evolution reaction, Electrochim. Electrochim. Acta 2018, 259, 955-961.

(51) Xie, Z.; Tang, H.; Wang, Y. MOF-Derived Ni-Doped $\mathrm{CoS}_{2}$ Grown on Carbon Fiber Paper for Efficient Oxygen Evolution Reaction. ChemElectroChem 2019, 6, 1206-1212.

(52) Kong, W.; Luan, X.; Du, H.; Xia, L.; Qu, F. Enhanced electrocatalytic activity of water oxidation in alkaline medium by $\mathrm{Fe}$ doping in $\mathrm{CoS}_{2}$ nanosheet. Chem. Commun. 2019, 55, 2469-2472.

(53) Lu, J.; Cai, L.; Zhang, N.; Qiu, B.; Chai, Y. Robust Photoelectrochemical Oxygen Evolution with N, Fe- $\mathrm{CoS}_{2}$ Nanorod Arrays. ACS Appl. Mater. Interfaces 2019, 11, 44214-44222.

(54) Wang, M.; Zhang, W.; Zhang, F.; Zhang, Z.; Tang, B.; Li, J.; Wang, X. Theoretical Expectation and Experimental Implementation of In Situ Al-Doped $\mathrm{CoS}_{2}$ Nanowires on Dealloying-Derived Nanoporous Intermetallic Substrate as an Efficient Electrocatalyst for Boosting Hydrogen Production. ACS Catal. 2019, 9, 1489-1502.

(55) Wang, Y.; Jian, C.; Hong, W.; Cai, Q.; Liu, W. Tuning the electron status of urchin-like $\mathrm{CoS}_{2}$ nanowires by selenium doping toward highly efficient hydrogen evolution reaction. Mater. Lett. 2019, 257, 126673-126676.

(56) Zhang, J.; Liu, Y.; Sun, C.; Xi, P.; Peng, S.; Gao, D.; Xue, D. Accelerated Hydrogen Evolution Reaction in $\mathrm{CoS}_{2}$ by TransitionMetal Doping. ACS Energy Lett. 2018, 3, 779-786.

(57) Shi, Z. T.; Qi, Y.; Zhang, J.; Guo, C. C.; Zhu, Z. H. CarbonBased Metallic Cobalt Pyrite Nanotubes as Stable Electrode Materials for Electrochemical Hydrogen Evolution. ACS Appl. Nano Mater. 2020, 3, 8335-8342.

(58) Kresse, G.; Hafner, J. Ab initio molecular dynamics for liquid metals. Phys. Rev. B: Condens. Matter Mater. Phys. 1993, 47, 558-561.

(59) Perdew, J. P.; Burke, K.; Ernzerhof, M. Generalized gradient approximation made simple. Phys. Rev. Lett. 1996, 77, 3865-3868. 